\title{
Antalya ilinde örtüaltı sebze üretim alanlarında ticari boyutta kullanılan biyolojik mücadele etmenleri
}

\section{Biological control agents used at commercial scale in greenhouse vegetable production areas in Antalya province}

\author{
Musa KIRIŞIK ${ }^{1}$, Fedai ERLER ${ }^{2}$ \\ ${ }^{1}$ Batı Akdeniz Tarımsal Araştırma Enstitüsü, Bitki Sağıl̆̆ı Bölümü, 07100 Antalya \\ ${ }^{2}$ Akdeniz Üniversitesi, Ziraat Fakültesi, Bitki Koruma Bölümü, 07070 Antalya \\ Sorumlu yazar (Corresponding author): F. Erler, e-posta (e-mail): erler@akdeniz.edu.tr
}

\section{MAKALE BİLGİSI}

Alınıs tarihi 05 Nisan 2017

Düzeltilme tarihi 24 Temmuz 2017

Kabul tarihi 24 Temmuz 2017

\section{Anahtar Kelimeler:}

Örtüaltı sebze yetiştiriciliği

Doğal düşman

Predatör

Parazitoit

Antalya

\begin{abstract}
ÖZ
Türkiye'de örtüaltı üretiminin yaygın olarak yapıldığı yerlerin başında Antalya ili gelmektedir İldeki örtüaltı üretiminde domates, biber, hıyar ve patlıcan en yaygın yetiştirilen bitkiler olmakla birlikte kavun, karpuz, kabak, kesme çiçeklerden de karanfil ve gerbera yetiştiriciliğ de son yıllarda yaygınlaşmıștır. Örtüaltı yetiştiriciliğinde hiç şüphesiz en önemli husus, zararlı ve hastalıklarla mücadeledir. Zararlı ve hastalık mücadelesi genelde sentetik kimyasal ilaç kullanımına dayanmakla birlikte son on yıldır biyolojik mücadele çalışmaları bazı ürünlerde, özellikle de biberde, hız kazanmış hatta Antalya'nın bazı yerlerinde (örneğin, Demre yöresinde) biberde başta Batı çiçek tripsi Frankliniella occidentalis (Pergande) (Thysanoptera: Thripidae) olmak üzere bazı zararlıların mücadelesi artık biyolojik ajanlarla yapılmaktadır. Bu derleme çalışmada, Antalya'da örtüaltı sebze yetiştiriciliğinde ticari boyutta kullanılan biyolojik mücadele etmenleri üzerine detaylı bilgi sunulmuştur.
\end{abstract}

\section{ARTICLE INFO}

Received 05 April 2017

Received in revised form 24 July 2017

Accepted 24 July 2017

\section{Keywords:}

Greenhouse vegetable growing

Natural enemy

Predator

Parasitoid

Antalya

\begin{abstract}
Antalya province is at the top of places in Turkey where indoor plant production is common. Although tomato, pepper, cucumber and eggplant are the most commonly grown plants in greenhouse production in the province, melon, watermelon, zucchini, and some cut-flowers such as carnation and gerbera growing has also become common in recent years. Undoubtedly, the most important issue in greenhouse production is the management of pests and diseases. Pest and disease management is based mainly on the use of synthetic chemical pesticides, but biological control efforts have been accelerated in some crops, especially in pepper, even in some parts of Antalya (for example in Demre district) the control of some pests, especially the western flower thrips, Frankliniella occidentalis (Pergande) (Thysanoptera: Thripidae), is now made with biological agents. In this review study, detailed information on the biological control agents used in the commercial scale in the greenhouse vegetable growing in Antalya was presented.
\end{abstract}

\section{Giriş}

Antalya ili, coğrafi konumu ve ekolojik avantajlarından dolayı Türkiye'de örtüaltı yetiştiriciliğinin yoğun olarak yapıldığı yerlerin başında gelmektedir. Ülkemizdeki toplam sera alanının yaklaşık \% 47 kadarı bu ilde bulunmaktadır. Yine en fazla taze sebze ihracatının yapıldığı il Antalya'dır (TÜİK 2015). İldeki örtüaltı üretiminde en yaygın yetiştirilen ürün domates olup, onu sırasıyla hıyar ve biber takip etmektedir. Ancak üretilen bu ürünlerin sadece \% 4-10 kadarı ihraç edilebilmektedir (AKİB/MEU 2015).

Antalya ilindeki örtüaltı yetiştiriciliğinde hiç şüphesiz en önemli sorun, zararlı ve hastalıklarla mücadele olup, genelde kimyasal ilaç kullanımına dayanmaktadır. Bu da zamanla zararlı ve hastalıklarda direnç gelişimine, ürünlerde kalıntı problemine ve daha da önemlisi çevre ve başta insanlar olmak üzere hedef dışı organizmalarda zarara yol açmaktadır. Zaman zaman kalıntı sorunundan dolayı örtüaltında üretilen birçok ürünün ihraç edilen ülkelerden geri döndüğüne şahit olunmaktadır (AKİB/MEU 2015). Kimyasal ilaç kullanımıyla ortaya çıkan tüm bu sorunların üstesinden gelebilmek için biyolojik mücadeleye önem vermek son derece gerekli bir yaklaşımdır.

Biyolojik mücadele, zararlı popülasyonları üzerinde etkili olan doğal düşmanları (böcekler, akarlar, omurgalılar, entomopatojen funguslar, bakteriler, virüsler, vs.) kullanarak zararlıları ekonomik zarar eşiğinin altında tutabilen veya baskı 
altına alabilen bir mücadele yöntemidir. Doğal ekosistemlerde kendiliğinden süregelen 'doğal biyolojik mücadele'de birçok zararlının popülasyonu kontrol altındadır. Ancak modern tarımın uygulandığı örtüaltı yetiştiriciliğinde yapılacak biyolojik mücadele için, biyolojik mücadele etmenlerinin laboratuvarda kitle halinde üretilip belli aralıklarla salınması gerekmektedir. Son yıllarda Antalya ilindeki örtüaltı sebze yetiştiriciliğinde bazı ürünlerde ticari boyutta kullanılan doğal düşmanlarla yapılan biyolojik mücadele çalışmalarından başarılı sonuçlar alınmaktadır. $\mathrm{Bu}$ derleme çalışmada, örtüaltı sebze yetiştiriciliğinde ticari boyutta kullanılan biyolojik mücadele etmenleri hakkında detaylı bilgi verilecektir.

\section{2. Örtüaltı Sebze Yetiştiriciliğinde Önemli Bazı Zararlılar Ve Doğal Düsșmanları}

Antalya ili gerek ekolojik, gerekse iklimsel özelliklerinden dolayı zararlılar için uygun bir bölgedir. İldeki örtüaltı sebze yetiştiriciliğinde sorun olan başlıca zararlılar yapılan sörvey çalışmalarıyla belirlenmiş olup (Tunç ve Göçmen 1995; Ulubilir ve Yabaş 1996; Erler ve ark. 2010), Çizelge 1'de verilmiştir. Bu zararlılar ile mücadele yapılmadığ 1 takdirde hızla Ekonomik Zarar Seviyesi (EZS)'nin üzerine çıkabilmekte ve bazıları $\%$ 100'e varan ürün kayıplarına neden olabilmektedirler. Örtüaltı sebze yetiştiriciliğinde önemli oranda kayıp oluşturabilen bu zararlılar ile kimyasal mücadele, doğal dengenin bozulmasından dolayı zorlaşmıştır. $\mathrm{Bu}$ noktada, biyolojik mücadelenin iki ana hedefinden bahsetmek gerekmektedir. İlki, kimyasal kullanımını azaltmak ve böylece insan, çevre ve hayvan sağlığını korumak, ikincisi ise ekosistem içerisinde 'zararlı' olarak bilinen organizmaları neredeyse $\% 100$ 'e varan oranda baskı altına alabilen 'doğal düşmanları/faydalı organizmaları' korumaktır.

Zararlılarla biyolojik mücadelede etmen olarak kullanılan organizmalardan böcekler ve akarlar ticari boyutta ön plana çıkmaktadır. Böcek doğal düşmanlar, zararlılar ile ilişkileri bakımından 'predatörler' ve 'parazitoitler' olarak iki gruba ayrılırlar. Parazitoit, bir canlı (zararlı) üzerinde veya içerisinde yaşamını devam ettiren ve üzerinde yaşadığı konukçunun gelişmesini engelleyen ve zamanla onun ölümüne yol açan organizmalardır. Predatörler ise yaşamı boyunca birden fazla zararlı (av) bireyini tüketerek yaşam döngülerini tamamlarlar (Öncüer 1997; Demirbağ ve ark. 2008). Son yıllarda parazitoitler ve predatörler ile bunların zararlılar ile ilişkilerine dair çok sayıda araştırma yapılmıştır.

Örtüaltı sebze yetiştiriciliğinde önemli zararlıların başında gelen Kırmızı̈̈r̈̈mcekler (Acarina: Tetranychidae) birçok bitkide önemli zararlar meydana getirebilmektedir. Yüksek üreme kapasitesiyle bitkileri kısa sürede verimsiz hale getirebilirler. İldeki örtüaltı sebze yetiştiriciliğinde en önemli kırmızı̈rümcek türü Tetranychus urticae Koch. olup, mücadelesinde yaygın olarak kimyasallar kullanılmakta, bu da zamanla direnç problemine yol açmaktadır. Bu sebepten dolayı zararlıya karşı biyolojik mücadele önemli hale gelmektedir. İlk ticari biyolojik mücadele uygulaması, yurtdışında bu zararlıya karş1 1960'lı yıllarda hıyar serasında predatör akar Phytoseiulus persimilis Athias-Henriot (Acarina: Phytoseiidae) salımı ile yapılmış ve günümüzde de hala $P$. persimilis kırmızı̈rümcek mücadelesinde kullanılmaktadır (Van Lenteren ve Woets 1988). Ülkemizde $P$. persimilis'in ilk tespiti 1989 yılında yapılmıştır (Sekeroglu ve Kazak 1993). Ancak yürütülen faunistik ve etkinlik çalışmaları sonunda daha birçok akar ve böcek türü kırmızıörümcek avcıları olarak belirlenmiş (Soysal ve Yayla 1988; Sekeroglu ve Kazak 1993; Bulut ve Göçmen 2000; Colkesen ve Sekeroglu 2000; Can ve Çobanoğlu 2010; Çobanoğlu ve Kumral 2014) ve Çizelge 2'de verilmiştir. Bu faunistik çalışmalarda çok sayıda predatör tür tespit edilse de kırmızı̈rümceklere karşı ticari olarak $P$. persimilis, Amblyseius californicus (McGregor) (Acarina: Phytoseiidae), Feltialtae acarisuga Vallot (Diptera: Cecidomyiidae) ve Stethorus punctillum Weise (Coleoptera: Coccinellidae) kullanılmaktadır (Çizelge 3). Bu türler içerisinde A. californicus sıcak ve kuru hava şartlarına adaptasyonundan dolayı Antalya ilinde daha çok tercih edilmektedir (Şekil 1).

Çizelge 2. Yürütülen faunistik çalışmalar sonucu ülkemizde varlı̆̆ saptanan kırmızı̈rümcek avcıları.

Table 2. The predators of spider mites determined in the survey studies carried out in Turkey.

\begin{tabular}{|c|c|c|}
\hline Takım & Familya & Tür \\
\hline Acarina & $\begin{array}{l}\text { Tydeidae } \\
\text { Laelapidae }\end{array}$ & $\begin{array}{l}\text { Phytoseiulus persimilis Athias-Henriot, } \\
\text { P. finitimus } \text { Ribaga, } \\
\text { Amblyseius californicus (McGregor), } \\
\text { A. longispinnosus (Evans), } \\
\text { A. stipulatus Athias-Henriot, } \\
\text { A. setosa (Muma), } \\
\text { Neoseiulus bicaudus (Wainstein), } \\
\text { Euseius scutalis (Athias-Henriot), } \\
\text { Pronematus ubiquitus (McGregor), } \\
\text { Stratiolaelaps (=Hypoaspis) miles } \\
\text { Berlese }\end{array}$ \\
\hline Coleoptera & Coccinellidae & $\begin{array}{l}\text { Stethorus gilvifrons Mulstant, } \\
\text { S. punctillum Weise }\end{array}$ \\
\hline Diptera & Cecidomyiidae & Feltialtae acarisuga Vallot \\
\hline Hemiptera & $\begin{array}{l}\text { Lygaeidae } \\
\text { Miridae }\end{array}$ & $\begin{array}{l}\text { Orius minitus } \mathrm{L} . \text {, } \\
\text { O. niger (Wolff) } \\
\text { Pioris (=Neoclylus) erythrocephalus } \mathrm{F} . \\
\text { Campylomma diversicorn } \text { Reuter }\end{array}$ \\
\hline Neuroptera & Chrysopidae & Chrysoperla carnea (Stephens) \\
\hline
\end{tabular}

Çizelge 1. Antalya ilinde örtüaltı sebze yetiştiriciliğinde sorun olan önemli zararlılar.

Table 1. Important pest problems in greenhouse vegetable growing in Antalya province.

\begin{tabular}{lll}
\hline Zararlı & Takım/Familya & \multicolumn{1}{c}{ Tür } \\
\hline Kırmı̈ı̈rümcek & Acarina/Tetranychidae & Tetranychus urticae Koch \\
Beyazsinekler & Hemiptera/Aleyrodidae & Bemisia tabaci (Gennadius), Trialeurodes vaporariorum (Westwood) \\
Tripsler & Thysanoptera/Thripidae & Frankliniella occidentalis (Pergande), Thrips tabaci Lindeman \\
Yaprakbitleri & Hemiptera/Aphididae & Aphis gossypii Glover, Myzus persicae (Sulzer), Macrosiphum euphorbiae (Thomas) \\
Yaprak galerisinekleri & Diptera/Agromyzidae & Liriomyza bryoniae (Kaltenbach), L. huidobrensis (Blanchard), L. trifolii (Burgess) \\
Domates güvesi & Lepidoptera/Gelechiidae & Tuta absoluta (Meyrick) \\
\hline
\end{tabular}


Çizelge 3. Antalya ilinde örtüaltı yetiştiriciliğinde sorun olan önemli zararlılar ile mücadelede ticari boyutta kullanılan biyolojik etmenler ${ }^{\mathrm{a}, \mathrm{b}}$.

Table 3. Biological agents used in the commercial scale for the control of important pests in greenhouse growing in Antalya province.

\begin{tabular}{|c|c|c|}
\hline Zararlı & Biyolojik etmen & Zararlının hedef biyolojik dönemi \\
\hline \multirow[t]{4}{*}{ Kırmızı̈̈rümcek } & Phytoseiulus persimilis Athias-Henriot & Yumurta, nimf, ergin \\
\hline & Amblyseius californicus (McGregor) & Yumurta, nimf, ergin \\
\hline & Feltialtae acarisuga Vallot & Yumurta, nimf, ergin \\
\hline & Stethorus punctillum Weise & Yumurta, nimf, ergin \\
\hline \multirow[t]{5}{*}{ Beyazsinekler } & Encarsia formosa Gahan & Nimf ve pupa \\
\hline & Eretmocerus eremicus Rose and Zolner. & 2. ve 3. dönem nimf \\
\hline & Delphastus catalinae (Horn) & Yumurta ve nimf \\
\hline & Macrolophus caliginosus Wagner & Yumurta ve nimf \\
\hline & Nesidiocoris tenuis (Reuter) & Yumurta ve nimf \\
\hline \multirow[t]{3}{*}{ Tripsler } & Amb. cucumeris (Oudemans) & Larva \\
\hline & Amb. swirskii Athias-Henriot & Larva \\
\hline & Orius spp. & Larva ve ergin \\
\hline \multirow[t]{8}{*}{ Yaprakbitleri } & Aphidius colemani Viereck & Ergin \\
\hline & Aph. ervi Haliday & Ergin \\
\hline & Aphelinus abdominalis Dalman & Ergin \\
\hline & Aphidoletes aphidimyza (Rondani) & Nimf ve ergin \\
\hline & Chrysoperla carnea (Stephens) & Nimf ve ergin \\
\hline & Episyrphus balteatus (De Geer) & Nimf ve ergin \\
\hline & Orius spp. & Nimf ve ergin \\
\hline & Adalia bipunctata (L.) & Nimf ve ergin \\
\hline \multirow[t]{2}{*}{ Yaprak galerisinekleri } & Diglyphus isaea (Walker) & Larva \\
\hline & Dacnusa sibirica Telenga & Larva \\
\hline \multirow[t]{2}{*}{ Domates güvesi } & Macrolophus caliginosus (Wagner) & Yumurta ve larva \\
\hline & Nesidiocoris tenuis (Reuter) & Yumurta ve larva \\
\hline
\end{tabular}

${ }^{\mathrm{a}}$ https://www.koppert.com/products/products-pests-diseases/.

${ }^{\mathrm{b}} \mathrm{http}: / /$ www.biobest.com.tr/urunListesi.aspx? Kategorild=2.

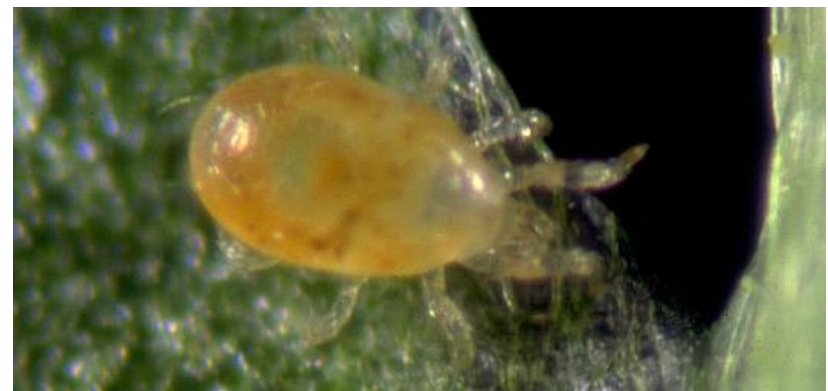

Șekil 1. Antalya ilinde örtüaltı yetiștiriciliğinde kırmızıörümceklere karşı ticari boyutta kullanılan predatör akar Amblyseius californicus.

Figure 1. The predatory mite, Amblyseius californicus, used in the commercial scale against the red spider mites in greenhouse growing in Antalya province.

Antalya ilinde örtüaltı sebze yetiştiriciliğinde önemli bir diğer zararlı grubu ise beyazsinekler (Hemiptera: Aleyrodidae) olup, 2 türü yaygın olarak bulunmaktadır. Bunlar; Bemisia tabaci Genn. ve Trialeurodes vaporariorum (Westwood)'dur. Encarsia formosa Gahan (Hymenoptera: Aphelinidae) beyazsineklere karşı tespiti yapılan ilk parazitoit tür olup, 1924 yılında beyazsinekleri parazitlediği bildirilmiştir (Gahan 1924). $\mathrm{Bu}$ tür, sebze yetiştiriciliğinde önemli zararlara neden olan beyazsineklere (B. tabaci ve T. vaporariorum) karş1 1972 y1lından beri kullanılmaktadır (Malais ve Ravensberg 2003). E. formosa dişında beyazsineklerle beslenen veya parazitleyen ve beyazsinekleri baskı altına alabilen başka türler de mevcuttur (Gerling 1986; Parrella ve ark. 1992; Polaszek ve ark. 1992; Legaspi ve ark. 1994; Vacante ve ark. 1994; Ulubilir ve Yabaş 1996; Riley ve Ciomperlik 1997; Bográn ve ark. 1998). Parazitoit türlerin neredeyse tamamını Hymenoptera takımına ait arıcıklar oluşturmaktadır (Çizelge 4). Yapılan çalışmalarda beyazsineklere karşı çok sayıda parazitoit ve predatör tür tespit edilse de bu türler içerisinde E. formosa, Eretmocerus eremicus Rose and Zolnerowich (Hymenoptera: Aphelinidae), Delphastus catalinae (Horn) (Coleoptera: Coccinellidae) Macrolophus caliginosus (Wagner) ve Nesidiocoris tenuis (Reuter) (Hemiptera: Miridae) Antalya ilinde ticari boyutta kullanılmaktadır (Çizelge 3). Beyazsineklerle mücadelede parazitoit E. eremicus (Şekil 2), yüksek sicaklıklardaki performans1, pestisitlere tolerans1 ve parazitleme oran1 bakımından diğer ticari parazitoit E. formosa'dan daha iyidir (Malais ve Ravensberg 2003). Predatör N. tenuis iyi bir beyazsinek avcısı olmasına rağmen, beyazsinek bulamadığı zaman bitkiyle beslenmekte ve bitki gelişimine zarar verebilmektedir (Malausa 1989; Vacante ve Tropea-Garcia 1994; Arnó ve ark. 2006).

Çizelge 4. Yapılan faunistik çalışmalar sonucu beyazsineklerle beslendiği saptanan parazitoit ve avcılar.

Table 4. The parasitoids and predators of whiteflies determined in survey studies.

\begin{tabular}{|c|c|c|}
\hline Takım & Familya & Tür \\
\hline \multirow[t]{4}{*}{ Hymenoptera } & Aphelinidae & $\begin{array}{l}\text { Eretmocerus spp. } \\
\text { Encarsia } \mathrm{spp} .\end{array}$ \\
\hline & Signiphoridae & Signiphora aleyrodis (Ashmead) \\
\hline & Encyrtidae & Metaphycus sp. \\
\hline & Platygasteridae & Amitus spp. \\
\hline Coleoptera & Coccinellidae & $\begin{array}{l}\text { Delphastus pusillus (LeConte) } \\
\text { D. catalinae (Horn) }\end{array}$ \\
\hline \multirow[t]{3}{*}{ Hemiptera } & Geocoridae & $\begin{array}{l}\text { Geocoris punctipes Fallen } \\
\text { G. pallens Stal. } \\
\text { Piocoris spp. }\end{array}$ \\
\hline & Anthocoridae & Orius spp. \\
\hline & Miridae & $\begin{array}{l}\text { Macrolophus caliginosus (Wagner) } \\
\text { Nesidiocoris tenuis (Reuter) }\end{array}$ \\
\hline Neuroptera & Chrysopidae & Chrysoperla carnea (Stephens) \\
\hline
\end{tabular}




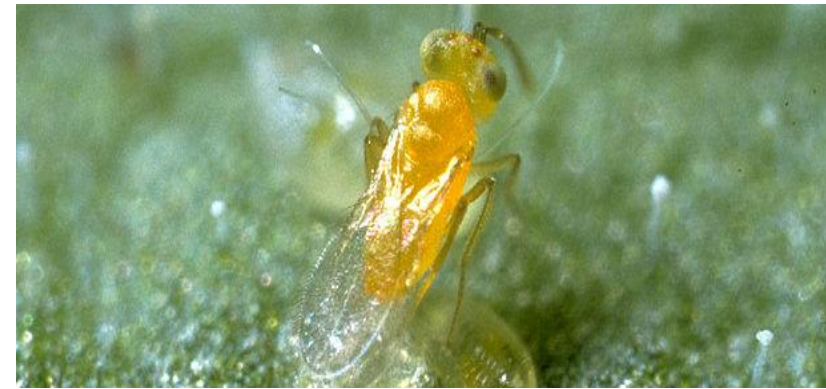

Şekil 2. Antalya ilinde örtüaltı yetiştiriciliğinde beyazsineklere karşı ticari boyutta kullanılan parazitoit arıcık Eretmocerus eremicus.

Figure 2. The parasitic wasp, Eretmocerus eremicus, used in the commercial scale against the whiteflies in greenhouse growing in Antalya province.

Antalya ilindeki örtüaltı sebze yetiştiriciliğinde önemli bir diğer zararlı grubu tripsler (Thysanoptera: Thripidae)'dir. Tripsler, bitkilerde sokup emerek beslenmeleri yanında birçok virüsün vektörlüğünü yaparak da zararlı olabilmektedirler (Allen ve Broadbent 1986). Örtüaltı sebze yetiştiriciliğinde iki trips türü [Frankliniella occidentalis (Pergande) ve Thrips tabaci Lindeman] tespit edilse de bunlardan en yaygını F. occidentalis'tir (Tunç ve Göçmen 1994; Atakan ve ark. 1998). Yapılan faunistik çalışmalarda tripslerin doğal düşmanları olarak birçok tür tespit edilmiş olup (Hessein ve Parrella 1990; Higgins 1992; Gabarra ve ark. 1995; Riudavets ve Castañé 1998; Bulut ve Göçmen 2000), bunların tamamı predatördür (Çizelge 5). Tespit edilen bu türler içerisinde Amblyseius cucumeris (Oudemans) ve A. swirskii AthiasHenriot (Acarina: Phytoseiidae) ile Orius spp. (Hemiptera: Anthocoridae) tripslerin önemli avc1ları olup Antalya ilinde ticari boyutta özellikle örtüaltı biber yetiştiriciliğinde kullanılmaktadır. Amblyseius spp. daha çok tripsin larvalarıyla, Orius spp. ise daha çok erginleri ile beslenmektedir (Malais ve Ravensberg 2003). Dolayisıyla trips mücadelesinde predatör akar ve predatör böceğin kombine halde kullanılması biyolojik kontrol açısından önemlidir. A. cucumeris aynı zamanda T. urticae larvaları ile de beslenebilmektedir (Şekil 3).

Antalya ilindeki örtüaltı sebze yetiştiriciliğinde önemli bir diğer zararlı grubu ise yaprakbitleri (Hemiptera: Aphididae)'dir. 'Afitler' ya da 'püsöronlar' olarak da bilinen bu zararlı grubu ile mücadele yüksek üreme gücüne sahip olmaları nedeniyle oldukça zordur. Ayrıca bu grup zararlılar, virüs vektörü olmalarından dolayı da önem kazanmaktadırlar. Yaprakbitleri, bitkilerde hastalık oluşturan 370 adet virüsün $\% 66$ 'sını taşımaktadırlar (Matheus 1993). Yaprakbitlerinin doğal düşmanları üzerine yapılan çalışmalarda gerek parazitoit gerekse predatör birçok tür tespit edilmiş olup (Zeren ve Düzgüneş 1983; Atakan ve Özgür 1994; Ulusoy ve ark. 1999; Bulut ve Göçmen 2000), bunlar Çizelge 6'da verilmiştir. Yaprakbitlerinin çok sayıda parazitoit ve predatörü belirlenmiș olmasına rağmen, günümüzde bunlardan Antalya İli örtüaltı sebze yetiştiriciliğinde Aphidius colemani Viereck ve A. ervi Haliday (Hymenoptera: Aphidiidae), Aphelinus abdominalis Dalman (Hym.: Aphelinidae), Aphidoletes aphidimyza (Rondani) (Diptera: Cecidomyiidae), Episyrphus balteatus (De Geer) (Dip.: Syrphidae), Chrysoperla carnea (Stephens) (Neuroptera: Chrysopidae), Orius spp. (Hemiptera: Anthocoridae) ve Adalia bipunctata (L.) (Coleoptera: Coccinellidae) türleri ticari boyutta kullanılmaktadır (Çizelge 3, Şekil 4). A. colemani, A. ervi ve A. abdominalis türleri tamamen yaprakbitlerine spesifik parazitoitlerdir. Yaprakbiti popülasyonunun düşük olduğu zamanlarda Aphidius türleri başarılı olabilmekte, ancak popülasyonun yoğun olduğu zamanlarda predatör ve parazitoitlerin birlikte salınması başarı şansını arttırmaktadır (Malais ve Ravensberg 2003).

Çizelge 5. Yapılan faunistik çalışmalar sonucu ülkemizde tripsler ile beslendiği saptanan predatör türler.

Table 5. The predators of thrips determined in the survey studies carried out in Turkey.

\begin{tabular}{cll}
\hline Takım & Familya & Tür \\
\hline Acarina & Phytoseiidae & Amblyseius cucumeris (Oudemans) \\
& & A. swirskii Athias-Henriot \\
& & A. degenerans (Berlese) \\
& & A. barkeri (Hugues) \\
& & A. californicus (McGregor) \\
Hemiptera & Anthocoridae & Orius spp. \\
& Miridae & Macrolophus caliginosus (Wagner) \\
\hline
\end{tabular}

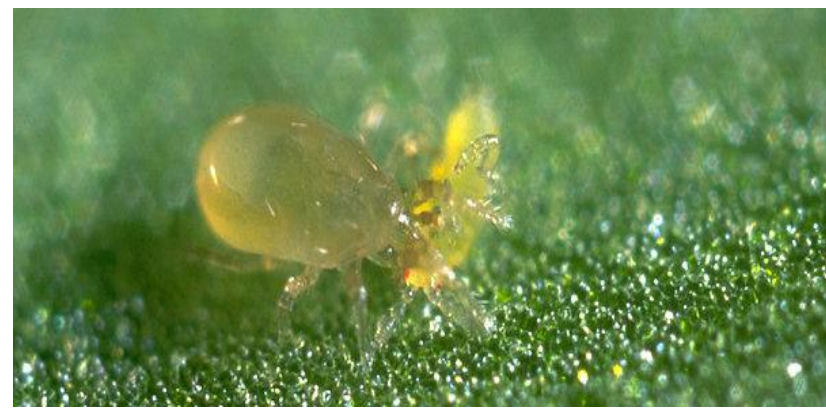

Şekil 3. Antalya ilinde örtüaltı yetiştiriciliğinde tripslere karşı ticari boyutta kullanılan predatör akar Amblyseius cucumeris.

Figure 3. The predatory mite, Amblyseius cucumeris, used in the commercial scale against the thrips in greenhouse growing in Antalya province.

Çizelge 6. Yapılan faunistik çalışmalar sonucu ülkemizde yaprakbitleriyle beslendiği tespit edilen parazitoit ve avc1lar.

Table 6. The parasitoids and predators of aphids determined in the survey studies carried out in Turkey.

\begin{tabular}{|c|c|c|}
\hline Takım & Familya & Tür \\
\hline \multirow[t]{10}{*}{ Hymenoptera } & Aphidiidae & Aphidius colemani Viereck \\
\hline & & A. ervi Haliday \\
\hline & & Trioxys anqelicae (Haliday) \\
\hline & Aphelinidae & Aphelinus abdominalis Dalman \\
\hline & Braconidae & Diaeretiella rapae (Macintosh) \\
\hline & & Ephedrus persicae (Frogatt) \\
\hline & & Lysiphlebus ambiguus (Haliday) \\
\hline & & Praon volucre (Haliday) \\
\hline & Pteromalidae & Asaphes vulgaris Walker \\
\hline & Encyrtidae & Syrhophagus aphidivorus (Mayr) \\
\hline \multirow[t]{3}{*}{ Diptera } & Cecidomyiidae & Aphidoletes aphidimyza (Rondani) \\
\hline & Syrphidae & Syrphus spp. \\
\hline & & Episyrphus balteatus (De Geer) \\
\hline Neuroptera & Chrysopidae & Chrysoperla carnea (Stephens) \\
\hline \multirow[t]{4}{*}{ Coleoptera } & Coccinellidae & Coccinella septempunctata $\mathrm{L}$. \\
\hline & & Adalia bipunctata (L.) \\
\hline & & Adonia variegata (Goeze) \\
\hline & & Scymnus spp. \\
\hline \multirow[t]{3}{*}{ Hemiptera } & Geocoridae & Geocoris spp. \\
\hline & Anthocoridae & Orius spp. \\
\hline & Miridae & Dicyphus tamaninii Walker \\
\hline
\end{tabular}


Antalya ilinde örtüaltı sebze yetiştiriciliğinde yukarıda bahsedilen zararlı gruplarına göre daha az mücadele gerektiren bir diğer zararlı grup yaprak galerisinekleri (Diptera: Agromyzidae)'dir. Galerisineklerinin üç türü [Liriomyza bryoniae (Kaltenbach), L. huidobrensis (Blanchard) ve L. trifolii (Burgess)] belirlenmiş olmasına rağmen yaygın olanlar son ikisidir (Ulubilir ve Yabaş 1996; Tunç ve Göçmen 1995). Bunların doğal düşmanları üzerine yapılan çalışmalarda (Heinz ve Parrella 1990; Calabretta ve ark. 1995; Uygun ve Polatöz 1995; Bulut ve Göçmen 2000; Ulubilir ve Yabaş 1996), Hymenoptera takımından birçok türün yaprak galerisineklerinin parazitoitleri olduğu saptanmıştır (Çizelge 7). Ancak bu parazitoitlerden, Antalya ilinde örtüaltı sebze yetiştiriciliğinde ticari boyutta kullanılanları Diglyphus isaea (Walker) ve D. sibirica Telenga (Hym.: Eulophidae) türleridir (Çizelge 3, Şekil 5).

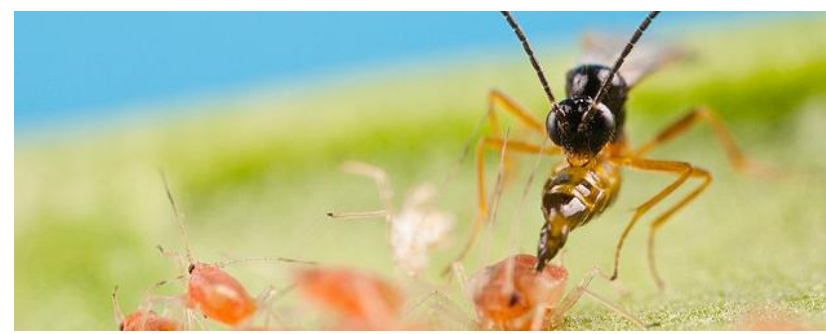

Şekil 4. Antalya ilinde örtüaltı yetiştiriciliğinde yaprakbitlerine karşı ticari boyutta kullanılan parazitoit arıcık Aphidius colemani.

Figure 4. The parasitic wasp, Aphidius colemani, used in the commercial scale against the aphids in greenhouse growing in Antalya province.

Çizelge 7. Yapılan faunistik çalışmalar sonucu yaprak gelerisineklerini parazitlediği saptanan hymenopter türler.

Table 7. The parasitic wasps of leafminers determined in survey studies.

\begin{tabular}{ccl}
\hline Takım & Familya & \multicolumn{1}{c}{ Tür } \\
\hline Hymenoptera & Eulophidae & Diglyphus isaea (Walker) \\
& & D. begini (Ashmead) \\
& D. crassinervis Erdos \\
& D. intermedius (Girault) \\
& Chrysonotomyia chlorogaster (Erdos) \\
& Neochrysocharis formosa (Westwood) \\
& Hemiptarsenus varicornis (Girault) \\
& Chrysocharis gemma (Walker) \\
& Braconidae & Dacnusa sibirica Telenga \\
\hline
\end{tabular}

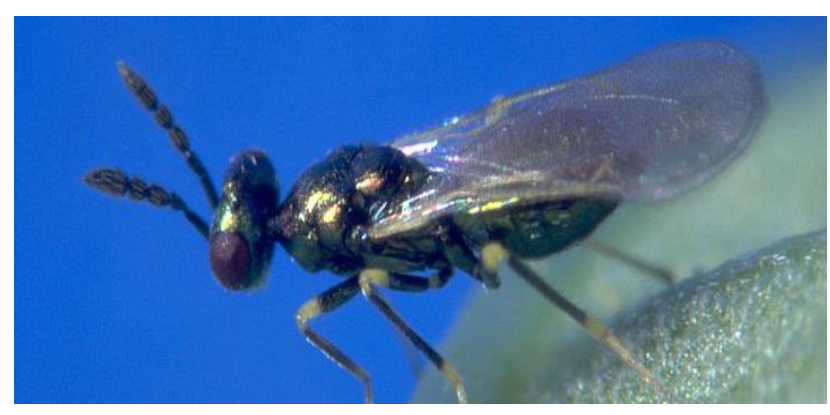

Şekil 5. Antalya ilinde örtüaltı yetiştiriciliğinde yaprak galerisineklerine karşı ticari boyutta kullanılan parazitoit arıcık Diglyphus isaea.

Figure 5. The parasitic wasp, Diglyphus isaea, used in the commercial scale against the leafminers in greenhouse growing in Antalya province.
Antalya ilinde örtüaltı domates yetiştiriciliğinde ilk olarak 2009 yılı Ekim ayında görülen Domates güvesi Tuta absoluta (Meyrick) (Lepidoptera: Gelechiidae) (Erler ve ark. 2010), sonraki yıllarda popülasyonunu ve zararını arttırmış, halen de ildeki örtüaltı domates yetiştiriciliğinin en önemli zararlısı konumundadır. Bir yandan zararlının doğal düşmanlarının belirlenmesi üzerine faunistik çalışmalar yapılırken, diğer yandan daha önce başka zararlılara karşı biyolojik etmen olarak kullanılan bazı türler ( $M$. caliginosus ve $N$. tenuis) zararlının biyolojik mücadelesi amaciyla ticari boyutta tavsiye edilmekte ve kullanılmaktadır (Çizelge 3).

\section{3. Örtüaltında Zararlılarla Biyolojik Mücadelenin Başarısını Etkileyen Faktörler}

Örtüaltı sebze yetiştiriciliğinde zararlılara karşı biyolojik mücadelede predatör ve parazitoitlerle ilgili bazen sorunlar yaşanabilmektedir. Bu sorunlara neden olan unsurlar aşağıdaki gibi sıralanabilir (K1lınçer ve ark. 2010).

\subsection{Avcıdan kaynaklanan olumsuzluklar}

Bazı predatörler (avcılar) av bulamadıkları zaman bitki ile beslenebilmekte ve bitki gelişimine zarar verebilmektedirler. Örneğin; $N$. tenuis iyi bir beyazsinek avcısı olmasına rağmen av bulamadığı zamanlarda bitki ile beslenebilmektedir. Bazı avcıların salımı, zararlı yoğunluğunun düşük olduğu zamanlarda yapıldığında bitkisel besin alamaz ve ölür. Örneğin, $P$. persimilis kendine av bulamazsa polen veya diğer alternatif besinlerle beslenemez ve ölür. Bu nedenle biyolojik mücadelede preadatör ve parazitoit davranışlarını iyi bilmek ve uygulama zamanını doğru tercih etmek önemlidir.

\subsection{Salım uygulamalart}

Başarılı bir biyolojik mücadele için, serada zararlı görülür görülmez predatör veya parazitoitler (veya her ikisi) salınmalıdır. Eğer salınacak biyolojik etmen, zararlı uygun yoğunluğa ulaşana kadar kendisine polen gibi besin bulabiliyor ise daha öncede salınabilir. Başarı şansını artırmak için erken salım önemlidir. Biyolojik etmen, ilgili firmanın etikette belirttiği oranda araziye salınmalıdır. Araziye salımda çok geç kalınmamalı ve firmadan alınan predatör veya parazitoitler serada uygulanana kadar uygun biçimde muhafaza edilmelidir.

\section{3. İklim şartlart}

Örtüaltı sebze üretiminin özellikle kışın yapıldığı zamanlarda zaman zaman sıcaklıklar oldukça düşmektedir. Bu ise predatör ve parazitoitlerin aktivitesini engelleyebilmektedir. Bahara doğru sıcaklıkların artması ile predatör ve parazitoitlerin etkinliği de artmaya başlamakta, ancak zararlıların genelde gelişme eşikleri daha düşük olduğundan yoğunlukları çok yüksek seviyelere ulaşmakta ve biyolojik etmenler bunları baskı altına almakta yetersiz kalmakta ve zarar oluşmaktadır.

\subsection{Pestisitlerin etkisi}

Biyolojik etmenler ilaçlara karşı daha çok duyarlı olup özellikle insektisit uygulamalarından oldukça fazla etkilenmektedirler. Pestisitlerin zararlının doğal düşmanlarının aktivitesini azalttığına veya onları tamamen ortadan kaldırdığına dair çok sayıda örnek mevcuttur. Biyolojik etmen salınan seralarda bunlara zarar vermeyen pestisitler uygulanmalıdır. Ayrıca hastalıklara karşı kullanılan ilaçların da biyolojik etmenlere olan etkisinin iyi araştırılıp öyle uygulanması gerekir. 


\subsection{Parazitoit pupası bulanan yaprakların kopartılması}

Üreticiler zaman zaman sebzelerin yaşlı yapraklarını koparmakta ya da yaprak budaması yapabilmektedir. Bu yapraklar üzerinde parazitoit pupalarının olabileceği hatırdan çıkarılmamalıdır. Bu yüzden koparılan yapraklar seradan dışarı atılmamalı, bir köşede tutularak parazitoit çıkışına izin verilmelidir.

\subsection{Sera içi ve çevre temizliği}

Sera içinde ve etrafinda bulunan yabancı otlar, hasat artıkları gibi zararlıların kıșlama alanları yok edilmelidir. Böylece zararlı popülasyonu azalacak ve faydalı organizmalar zararlıları daha rahat şekilde kontrol altına alabileceklerdir.

\section{Sonuç}

Örtüaltı sebze üretim alanları, kimyasal ilaç uygulamalarının en yoğun yapıldığı alanlardır. Bu uygulamalar insan, çevre ve hayvan sağlığını tehdit etmekte ve giderek doğanın dengesini bozmaktadır. Biyolojik mücadele bu noktada önemli hale gelmektedir. Zararlılarla entegre mücadele çalışmalarında da biyolojik mücadele etkin bir rol almalıdır. Üretim alanlarında mevcut bulunan yerli biyolojik etmenler korunmalı, hatta bunların popülasyonlarının arttırılmasına yönelik çalışmalar yapılmalıdır. Söz konusu bu etmenler yörenin iklim şartlarına adapte olduğundan mümkün ise kitlesel üretimi çalışılmalıdır. Yurtdışından ithal edilen biyolojik etmenler için oldukça yüksek maliyetlere katlanmak yerine, yerli doğal düşmanların üretimini desteklemek biyolojik mücadelenin ülkemizdeki geleceği açısından son derece önem arz etmektedir.

\section{Kaynaklar}

AKİB/MEU (2015) İhracat Rakamları 2015. http://www.akib.org.tr. Erişim 9 Mart, 2017.

Allen WR, Broadbent AB (1986) Transmission of tomato spotted wilt virus in Ontario greenhouses by Frankliniella occidentalis. Canadian Journal of Plant Pathology 8: 33-38.

Arnó J, Albajes R, Gabarra R (2006) Within-plant distribution and sampling of single and mixed infestations of Bemisia tabaci and Trialeurodes vaporariorum (Homoptera: Aleyrodidae) in winter tomato crops. Journal of Economic Entomology 99: 331-340.

Atakan E, Özgür AF (1994) Pamuk yaprakbiti (Aphis gossypii Glov.) (Aphididae)'nin populasyon gelişiminde doğal düşman etkinliğinin araştırılması. Türkiye III. Biyolojik Mücadele Kongresi, Cilt 1, İzmir, s. 25-28.

Atakan E, Özgür AF, Kersting U (1998) Frankliniella occidentalis (Thysanoptera: Thripidae) on cotton in Çukurova region. Sixth International Symposium on Thysanoptera, Cilt 1, Antalya, pp. 7-12.

Bográn CE, Obrycki JJ, Cave R (1998) Assessment of biological control of Bemisia tabaci (Homoptera: Aleyrodidae) on common bean in Honduras. Florida Entomologist 81: 384-395.

Bulut E, Göçmen H (2000) Pests and their natural enemies on greenhouse vegetables in Antalya (Turkey). IOBC/WPRS Bulletin 23(1): 33-38.

Calabretta C, Calabro M, Colombo A, Campo G (1995) Spreading of Liriomyza huidobrensis (Blanchard) (Diptera, Agromyzidae) in protected cultures in Sicily. Informatore Fitopatologico 45(6): 24-30.

Can M, Çobanoğlu S (2010) Kumluca (Antalya) ilçesinde sebze üretimi yapılan seralarda bulunan akar (Acari) türlerinin tanımı ve konukçuları üzerinde çalışmalar. Akdeniz Üniversitesi Ziraat Fakültesi Dergisi 23(2): 87-92.

Colkesen T, Sekeroglu E (2000) The effect of Amblyseius longispinosa Evans (Acarina: Phytoseiidae) on Tetranychus cinnabarinus Boisd. (Acarina: Tetranychidae) on different cucumber cultivars. IOBC/WPRS Bulletin 23(1): 187-193.

Çobanoğlu S, Kumral NA (2014) Ankara, Bursa ve Yalova illerinde domates yetiştirilen alanlarda zararlı ve faydalı akar (Acari) biyolojik çeşitliliği ve popülasyon dalgalanması. Türkiye Entomoloji Dergisi 38(2): 197-214.

Demirbağ Z, Nalçalıoğlu R, Katı H, Demir İ, Sezen K, Ertürk Ö (2008) Entomopatojenler ve Biyolojik Mücadele. Esen Ofset Matbaacılık, Trabzon.

Erler F, Can M, Erdogan M, Ates AO, Pradier T (2010) New record of Tuta absoluta (Meyrick) (Lepidoptera: Gelechiidae) on greenhousegrown tomato in Southwestern Turkey (Antalya). Journal of Entomological Science 45(4): 392-393.

Gabarra R, Castane C, Albajes R (1995) The mirid bug Dicyphus tamaninii as a greenhouse whitefly and western flower thrips predator on cucumber. Biocontrol Science and Technology 5(4): 475-488.

Gahan AB (1924) Some new parasitic Hymenoptera with notes on several described forms. Proceedings of the United States National Museum 65(4): 1-23.

Gerling D (1986) Natural enemies of Bemisia tabaci, biological characteristics and potential as biological control agents: a review. Agriculture, Ecosystems and Environment 17(1-2): 99-110.

Heinz KM, Parrella MP (1990) The influence of host size on sex ratios in the parasitoid Diglyphus begini (Hymenoptera: Eulophidae). Ecological Entomology 15: 391-399.

Hessein N, Parrella M (1990) Predatory mites help control thrips on floriculture crops. California Agriculture 44(6): 19-21.

Higgins CF (1992) ABC transporters: from microorganisms to man. Annual Review of Cell Biology 8(1): 67-113.

Kılınçer N, Yiğit A, Kazak C, Er MK, Kurtuluş A, Uygun N (2010) Teoriden pratiğe zararlılarla biyolojik mücadele. Türkiye Biyolojik Mücadele Dergisi 1: 15-59.

Legaspi JC, Carruthers RI, Nordlund DA (1994) Life-history of Chrysoperla rufilabris (Neuroptera: Chrysopidae) provided sweetpotato whitefly Bemisia tabaci (Homoptera: Aleyrodidae) and other food. Biological Control 4(2): 178-184.

Malais MH, Ravensberg WJ (2003) Knowing and Recognizing: The Biology of Glasshouse Pests and Their Natural Enemies. Reed Business Information, BA Doetinchem, The Netherlands.

Malausa JC (1989) Lutte intégrée sous serre: les punaises prédatrices Mirides dans les cultures de Solanacées du sud-est de la France. PHM-Revue Horticole 298: 39-43.

Matheus REF (1993) Diagnosis of Plant Virus Diseases. CRS Press Incorparation, Boca Raton, Florida.

Öncüer C (1997) Tarımsal Zararlılarla Biyolojik Savaş (Temel Bilgiler). 1. Baskı, Adnan Menderes Üniversitesi Yayınları, Aydın.

Parrella MP, Heinz KM, Nunney L (1992) Biological control through augmentative releases of natural enemies: a strategy whose time has come. American Entomologist 38(3): 172-180.

Polaszek A, Evans GA, Bennett FD (1992) Encarsia parasitoids of Bemisia tabaci (Hymenoptera: Aphelinidae, Homoptera: Aleyrodidae): a preliminary guide to identification. Bulletin of Entomological Research 82(3): 375-392.

Riley DG, Ciomperlik MA (1997) Regional population dynamics of whitefly (Homoptera: Aleyrodidae) and associated parasitoids (Hymenoptera: Aphelinidae). Environmental Entomology 26(5): 1049-1055. 
Riudavets J, Castañé C (1998) Identification and evaluation of native predators of Frankliniella occidentalis (Thysanoptera: Thripidae) in the Mediterranean. Environmental Entomology 27(1): 86-93.

Sekeroglu E, Kazak C (1993) First record of Phytoseiulus persimilis (Acari: Phytoseiidae) in Turkey. Entomophaga 38(2): 241-244.

Soysal A, Yayla A (1988) Preliminary studies on the population density of Tetranychus spp. (Acarina: Tetranychidae), harmful on vegetable crops and their natural enemies in Antalya. Bitki Koruma Bülteni 28(1-2): 29-41.

Tunç İ, Göçmen H (1994) New greenhouse pests, Polypahagotarsonemus latus (Banks) and Frankliniella occidentalis (Pergande) in Turkey. FAO Plant Protection Bulletin 42(3): 218-220.

Tunç İ, Göçmen H (1995) Antalya'da bulunan iki sera zararlısı Polyphagotarsonemus latus (Banks) (Acarina, Tarsonemidae) ve Frankliniella occidentalis (Pergande) (Thysanoptera, Thripidae) üzerine notlar. Türkiye Entomoloji Dergisi 19(2): 101-109.

TÜIK (2015) Bitkisel Üretim İstatistikleri 2015. http://www.turkstat.gov.tr/Start.do. Erişim 5 Mart, 2017.

Ulubilir A, Yabaş C (1996) Akdeniz Bölgesi'nde örtüaltında yetiştirilen sebzelerde görülen zararlı ve yararlı faunanın tespiti. Türkiye Entomoloji Dergisi 20(3): 217-228.
Ulusoy MR, Vatansever G, Uygun N (1999) Ulukısla (Niğde) ve Pozantı (Adana) yöresi kiraz ağaçlarında zararlı olan türler, doğal düşmanları ve önemlileri üzerindeki gözlemler. Türkiye Entomoloji Dergisi 23(2): 111-120.

Uygun N, Polatöz Z (1995) Faunistic studies on Agromyzidae (Diptera) in the South East Mediterranean Region of Turkey. Türkiye Entomoloji Dergisi 19(2): 123-136.

Vacante V, Cacciola SO, Pennisi AM (1994) Epizootiological study of Neozygites parvispora (Zygomycota: Entomophthoraceae) in a population of Frankliniella occidentalis (Thysanoptera, Thripidae) on pepper in Sicily. Entomophaga 39: 123-130.

Vacante V, Tropea-Garcia G (1994) Nesidiocoris tenuis: antagonista naturale di Aleirodidi. Informatore Fitopatologico 44(4): 23-28.

Van Lenteren JC, Woets JV (1988) Biological and integrated pest control in greenhouses. Annual Review of Entomology 33(1): 239-269.

Zeren O, Düzgüneş Z (1983) Çukurova Bölgesi’nde sebzelerde zararlı olan Aphidoidea türlerinin doğal düşmanları üzerinde araștırmalar. Türkiye Bitki Koruma Dergisi 7(3): 199-211. 